\title{
A Preliminary Study of Peat Gasification Characteristics in an Improved Biomass Stove
}

\author{
J.P. Simanjuntak ${ }^{1 *}$, B.H. Tambunan ${ }^{1}$, H. Efendi ${ }^{1}$, R. Silaban ${ }^{1}$, S. Riadi ${ }^{1}$, D. Pasaribu ${ }^{1}$ \\ $\{*$ janterps@unimed.ac.id $\}$ \\ ${ }^{1}$ Mechanical Engineering Department, Universitas Negeri Medan, Medan, North Sumatra, Indonesia
}

\begin{abstract}
The purpose of this research was to assess the ability of peat as fuels based on improved stove gasification. The stove was designed and fabricated refer to numerous stoves used by resesearchers and used as the appliance for validation. The stove tested was the forced draft types with a battery mini fan-assisted and a mini blower to force the controlled air for gasification requirement. Flame temperature was recorded and displayed using K-type thermocouple and thermometer indicator respectively. The laboratory operating parameter used was the equivalence ratio (ER) in the ranges of 0,20,45 . Three peat sizes different in diameters were considered to study the effect of ER on the flame temperature as the thermal power indicator of the peat. From the test results, it was found that the flames temperature was in the ranges $600-700{ }^{\circ} \mathrm{C}$. Peat with moderate diameter sizes (about $3 \mathrm{~cm}$ ) was acchieved higher flame temperature about $680{ }^{\circ} \mathrm{C}$ with ER was about 0,34 .
\end{abstract}

Keywords: Energy alternatif, biomass, peat, stove, combustion, gasification

\section{Introduction}

Due to the uncertainty of global price of the main fuel from year to year, and also the negative impact of greenhouse gas emission on the environment, alot of rural residents forced uses a huge amount solid fuel such as biomass and wood charcoal as fuel. Usually simple stoves are widely used as combustion appliance with a number of wasteful weaknesses in the use of solid fuels and also harmful air pollution. However, as technology continues to grow, solid fuel direct combustion methods using conventional three stones stoves have been abandoned and switch to the developed and improved stoves based on gasification.

In contrast to conventional three-stones, an improved stove design brings the thermal process of solid fuel near-stoichiometric operation to maximize thermal efficiency and minimize emissions, limits the velocities in the core of the stove as processing zone to limit particle carry-over with vessels of practical relevance was developed and well engineered using principles of gasification with air supply from battery assisted mini-fan and offer efficiency of ranged from $40 \%$ to $60 \%$.

Some improved stoves have been studied and are used for biomass conversion equipment [11]-[14],[21] . However, the information of peat gasification based on stove is still rare. Referring to the potential of renewable energy sources, in addition to biomass, peat (peat soil) is considered as renewable [16] but is not considered as biomass[20]. Peat is also available in abundance and has the potential as a fuel to replace wood charcoal and other fuels. Peat is known to be one of a competitive solid fuel based carbonaceous content as an alternative 
energy source. It is the lowest class of coal consisted of $54.5 \% \mathrm{C}, 5.1 \% \mathrm{H}, 1.65 \% \mathrm{~N}, 0.45 \% \mathrm{~S}$, $33.09 \% \mathrm{O}$ and $5.2 \%$ Ash with the High Heating Value of $21.230 \mathrm{~kJ} / \mathrm{kg}$ [1].

At this time, attention has been paid to upgrade the peat value based on heat energy content. In Indonesia, considerably effort have been made, however this effort increased slowly but surely. Thermal energy from peat can be upgraded by gasification instead of conventional direct combustion using an improved biomass stove. Gasification is well known as the most attractive process to biomass solid fuel due to less pollutant generation.

As one of the advantages uses of peat as fuel, it can reduce the risk of land fires which are usually occures in every dry season. Wildland actually very harmful and causes the carbon loses during fires. Another advantage is the restoration of peatlands which is useful for maintaining the sustainability of peat soil production. The use of peat is also helpful for mitigation to the global warming[6].

Indonesia has around 17 million hectares of peat land (10\% of Indonesian's area) and is spread throughout Sumatra, Kalimantan and Papua. Sumatera especially South Sumatra has the peatland about 1,4 million hectares and has not been utilized optimally. In general, peat can be used for household purposes in terms of energy sources. One of the most interesting of the peat disadvantages when processed using three-stone fire is the particles emission due to high ash content and has a significant effect on global warming than biomass.

By using an improved stove based gasification, $90 \%$ of the particulate matter can be reduced[15]. Indonesian peat has higher emission factor compare to wood[5][10]. Therefore, peat better gasify in combined or co-firing with another solid fuels [6][20] to reduce the particles emission. Considering that peat soil does not have a specific shape and size, in addition to the many water content constraints, its use is constrained in size. A study shows that the presence of peat and the energy it produces is beneficial for household needs by making its shape into briquettes [9].

This study focused on evaluating the ability of peat as thermal energy source-based biomass stove gasification. Specific objective is to obtain the parameter that suitable to convert the peat via gasification into flameable produts gas. Forced draft biomass stoves type is used in this study. Good mixing of air with product gases and can result in complete combustion in addition to low emissions are the advantages of this stove compare to open three stones. This stove is also well known as an attractive devicess due to its small sizes. The stove is made of thin plate material. The stove working principle is the force draft type based like most used by another researcher where a controlled air for gasification needed is supplied by a mini battery fan and a mini blower[22].

\section{Methodology}

\subsection{Materials}

This study investigated the viability of raw peat as an alternative fuel in rural area. Peats were collected from Dolok Sanggul district in the North Sumatera, $400 \mathrm{~km}$ from Medan. Peat samples were collected and naturally dried under the sunlight to remove water as much as possible before using as feedstock. Usually the water content of the peat was approximately $11 \%$ after drying[10]. The peat was formed manually nearly to spherical shape with diameter ranged from 1 to $3 \mathrm{~cm}$. 


\subsection{Method}

\subsubsection{Stove design and prototype}

The stove was fabricated at mechanical engineering workshop, engineering faculty, Universitas Negeri Medan. The stoves picture schematic diagram can be seen in Fig and its prototype is shown in Fig. The manufacture of the stove was made using thin plate materials and referring to theoretical design by[17]. This developed stove offers efficient applications, which make user friendly and sustainable in the rural society. The emissions from this stove are quite low, portable and can be operated indoors.

There are two air holes in this stove; the primary and the secondary air holes. The primary air directly supplied into the stove from the bottom side to gasification section and the secondary air is added from the slightly below upper side for product gas combustion. The peat was feed from the top of the stove just above the grate. This type of stove was generally named, the "Turbo Stove"[19].

An important parameter to operate this stove which based on gasification is the equivalence ratio (ER) aspect. According to [23] in their work, they used ER for biomass based wood gasification in downdraft reactor in the range $0.268-0.46$. The ER is a very important criterion for solid fuels since there is only one theoretical value that produces maximum flame temperature and minimum emissions. Mini fan and blower were performed to suply the air required for gasification in to the stove. The product flameable gases meets with oxygen at the top side and burnt produced hot flame.

\subsubsection{Experiment procedures}

In initiating the operation of this stove, certain of charcoal and kerosene were used to speed up the peat's ignition time. The peat was considered well-lit when it's colour was fisually observed fully red. Afterwards peat with diameters ranged from $1-3 \mathrm{~cm}$ are fed into the stove precisely above the grate. If longer time for testing is required, additional peat can be fed from the top of the stove. The time required for initial ignition should be as short as possible until the stove generated flame. After the fire arises from the stove, the experimental process begins, the fan air supply was turned on and the air flow was measured using anemometer.

The flame temperature during test-run is measured using a K-type thermocouple, viewed and recorded using a digital temperature indicator. Through the flame temperature and its colour, it can be possible to know the peat ability as the fuel. To evaluate the performance of the stove, the modified water boiling test (WBT 4.2.3) version was performed due to the lack of the instrument in the laboratory. This method performs well under some of difference in biomass and stove geometry. This protocol was also used by a number of researcher to evaluate their biomass fired stove[4][8][13][18]. The performance parameters studied in this work are thermal efficiency, specific fuel consumption and also the thermal output of the stove.

In this study, the peat tested assumed has a uniform sizes and diameter ranged from 1 to 3 $\mathrm{cm}$ in accordance with [2] and well dryed using solar thermal for 3 to 5 days. The amount of peat fuels used is measured using a digital scale. After flame arises and observed stable, 1 liter of water at ambient temperature in the pot is placed on the stove above of the support part. The stove condition for starting began from ambient temperature. Testing model refer to ambient temperature is called as the cold-start phase. The flame and the time during the operation is well recorded using K-type thermocouple after water get boiled. After that the fan is switch of and let the stove to cool down. The rest peat, water, and the ash after testing are weighed 
which used to calculate the stove efficiency. Efficiency is one of the most important parameters in the solid fuel testing. The transfer of energy from the fuel to the pot must be as high as possible. But the estimation of heat transfer in the stove is very complicated. In this study the efficiency of the stove is estimated using the principle of mass balance.

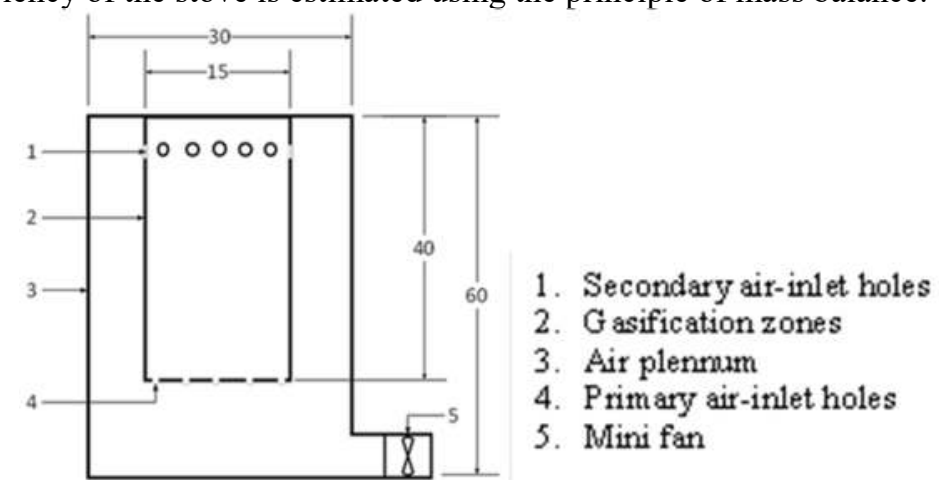

Fig. 1. Top-lit forced draft gas stove schematic diagram (in $\mathrm{cm}$ )

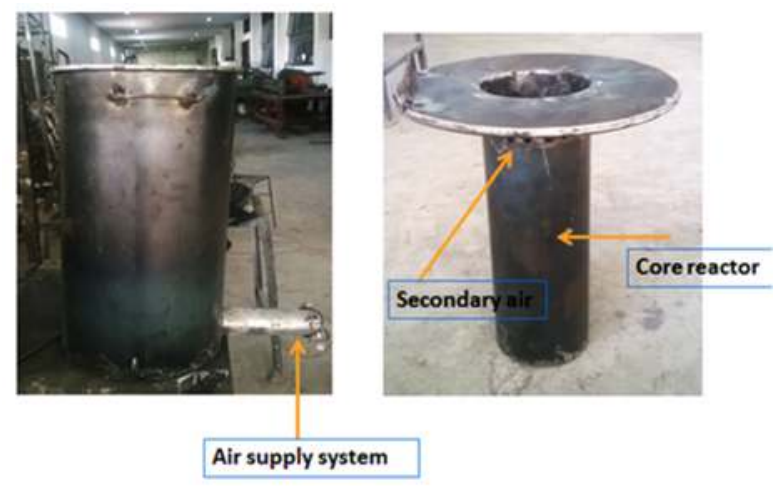

Fig. 2. The stoves prototype

\section{Result and Discussion}

The Turbo Stove studied in this project has been satisfactorily operated. Understanding the operation of the stoves tested has been achieved through the visual observations of the flames colour and temperature profiles during running-test. The stoves flame observed during experiment can be seen as shown in Fig. It has been observed that the stove burns continuously for 32 minutes. Clearly, the peat ability can be categorized valueable based on flames colour and the temperature. The flame temperature is in the ranges of $600-700{ }^{\circ} \mathrm{C}$ slightly below the temperature flame of wood gas[18]. The higher the flame temperature indicated higher thermal power output of the stove. The flame temperature obtained in this study is similar to the flame temperature-based stove by another researcher.

Fig shows the temperature profile of the flame during test run. It can be seen that the flames temperature varies with equivalence ratio and the peats diameter. It was found that for all three peats sample in this study, the flame temperature increases with increases equivalence 
ratio up to about 0,34 and than start to decrease. This condition is in accordance with the gasification theory where gasification occurs in the ER ranges between 2 to 3[2]. However, in the higher the ER, the flameable gases product starts to decrease because the thermal process in the stove become closer to the combustion process where all gasess tends to burn due to excess air and high temperatures in the stove. For good gasification, the air requirement is only a fraction of stoichiometric amount and below that the process becomes pyrolysis process that producess bio oil instead of fuell gasess.

It was found that the peat with moderate diameter size (about $3 \mathrm{~cm}$ ) was acchieved higher flame temperature about $680{ }^{\circ} \mathrm{C}$ with $\mathrm{ER}$ was about 0,34 during peak hour of the test run and than decrease. In this condition, the ability of the peat can also be observed through the colour of flame shown. This result is confirmed by the previews research through wood gasification in downdraft gasifier attain the higher Carbon monoxida and Methane content in the syngas on ER about $0,36[23]$.

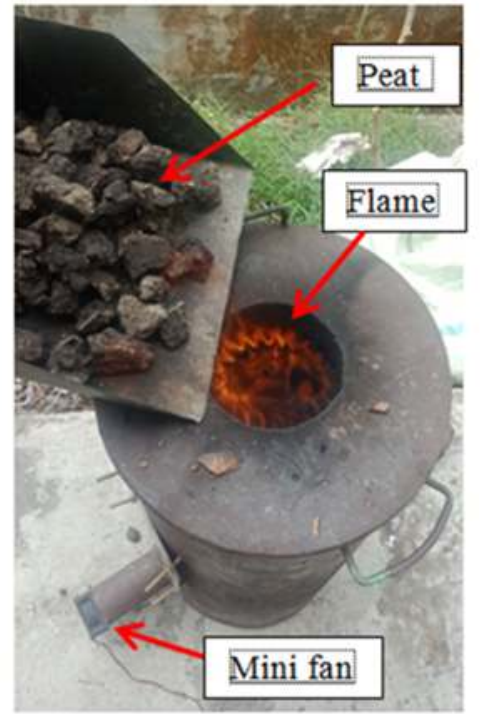

Fig. 3. The stove flame photoghrapic in operation

The decrease in the temperature with ER is due to decrease in the production of combustible gasess. Generally, by incresing the ER, the process close to combustion, so that apart of the gases burnt completely before meet the secondary air at the top to be burnt.

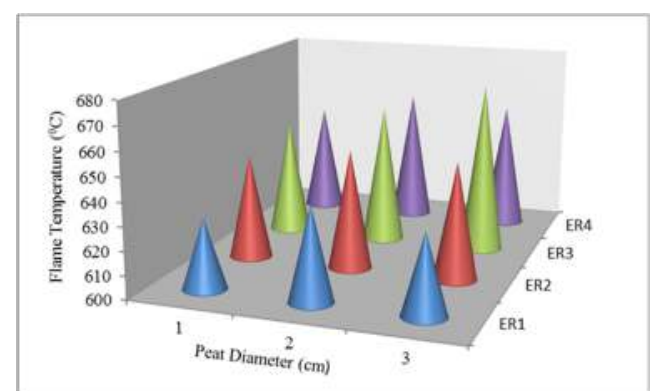

Fig. 4. Temperature profile of peat gasification 
Thermal efficiency of the stove using peat in this study is found approximately $23,7 \%$. This is similar with another researcher found [18] confirmed by the thermal eficiency of biomass close to $27 \%[3]$. The specific fuel consumption and the thermal output power obtained are quite comparable with previews findings on biomass gasification based on stove.

The results were carefully consulted to the standar protocol WBT under numerous works. In this study, performance of the stoves was evaluated by using the water boiling test (WBT). This protocol was also used by a number of researcher to evaluate their biomass fired stove [13][18]. The findings in this work were alot of similar with other results founded by researches.

\section{Conclusion}

A study on increase value of abundant energy sources of peat was performed based on laboratory conditions. An improved biomass stove was used to assess the ability of this solid fuel to respond and reduce dependence on fossil fuel and to help mitigation on environmental. The product flameable gas generated during process was combusted to observe the ability of this fuel based on temperature flames. High temperature about $680{ }^{\circ} \mathrm{C}$ can be achieved from the peat with ER was about 0,34. High temperature indicated that the peat can be used as an alternative energy sources especially in rural areas. An argumentatif conclusion can be drawn from this work that the peats have highly potential energi sources that must be further developed

\section{References}

[1] Basu, P. (2010) Biomass gasification and pyrolysis: practical design and theoryAcademic press.

[2] Basu, P. (2018) Biomass gasification, pyrolysis and torrefaction: practical design and theoryAcademic press.

[3] Bhattacharya, S., Attalage, R., Leon, M. A., Amur, G., Salam, P. A. \& Thanawat, C. (1999) Potential of biomass fuel conservation in selected Asian countries. Energy conversion and Management, 40(11), 1141-1162.

[4] Chen, Y., Shen, G., Su, S., Du, W., Huangfu, Y., Liu, G., Wang, X., Xing, B., Smith, K. R. \& Tao, S. (2016) Efficiencies and pollutant emissions from forced-draft biomass-pellet semigasifier stoves: Comparison of International and Chinese water boiling test protocols. Energy for Sustainable Development, 32, 22-30.

[5] Christian, T. J., Kleiss, B., Yokelson, R. J., Holzinger, R., Crutzen, P., Hao, W. M., Saharjo, B. \& Ward, D. E. (2003) Comprehensive laboratory measurements of biomass-burning emissions: 1. Emissions from Indonesian, African, and other fuels. Journal of Geophysical Research: Atmospheres, 108(D23).

[6] Dhillon, R. \& von Wuehlisch, G. (2013) Mitigation of global warming through renewable biomass. Biomass and Bioenergy, 48, 75-89.

[7] Fagerström, J., Näzelius, I.-L., Gilbe, C., Boström, D., Öhman, M. \& Boman, C. (2014) Influence of peat ash composition on particle emissions and slag formation in biomass grate co-combustion. Energy \& Fuels, 28(5), 3403-3411.

[8] Grimsby, L. K., Rajabu, H. M. \& Treiber, M. U. (2016) Multiple biomass fuels and improved cook stoves from Tanzania assessed with the Water Boiling Test. Sustainable Energy Technologies and Assessments, 14, 63-73. 
[9] Hakizimana, J. d. D. K. \& Kim, H.-T. (2016) Peat briquette as an alternative to cooking fuel: A techno-economic viability assessment in Rwanda. Energy, 102, 453-464.

[10] Iinuma, Y., Brüggemann, E., Gnauk, T., Müller, K., Andreae, M. O., Helas, G., Parmar, R. \& Herrmann, H. (2007) Source characterization of biomass burning particles: The combustion of selected European conifers, African hardwood, savanna grass, and German and Indonesian peat. Journal of Geophysical Research: Atmospheres, 112(D8).

[11] Jetter, J. J. \& Kariher, P. (2009) Solid-fuel household cook stoves: characterization of performance and emissions. Biomass and Bioenergy, 33(2), 294-305.

[12] Kumar, M., Kumar, S. \& Tyagi, S. (2013) Design, development and technological advancement in the biomass cookstoves: A review. Renewable and Sustainable Energy Reviews, 26, 265-285.

[13] L'orange, C., DeFoort, M. \& Willson, B. (2012) Influence of testing parameters on biomass stove performance and development of an improved testing protocol. Energy for Sustainable Development, 16(1), 3-12.

[14] Mehetre, S. A., Panwar, N., Sharma, D. \& Kumar, H. (2017) Improved biomass cookstoves for sustainable development: A review. Renewable and Sustainable Energy Reviews, 73, 672-687.

[15] Najjar, Y. S. \& Kseibi, M. M. (2017) Thermoelectric stoves for poor deprived regions-A review. Renewable and Sustainable Energy Reviews, 80, 597-602.

[16] Nehrenheim, E. (2018) Introduction to Renewable Energy, in Dellasala, D. A. \& Goldstein, M. I. (eds), Encyclopedia of the Anthropocene. Oxford: Elsevier, 405-406.

[17] Panwar, N. \& Rathore, N. (2008) Design and performance evaluation of a $5 \mathrm{~kW}$ producer gas stove. Biomass and Bioenergy, 32(12), 1349-1352.

[18] Raman, P., Murali, J., Sakthivadivel, D. \& Vigneswaran, V. (2013) Performance evaluation of three types of forced draft cook stoves using fuel wood and coconut shell. biomass and bioenergy, 49, 333-340.

[19] Reed, T., Anselmo, E. \& Kircher, K. (2000) Testing and modeling the wood-gas Turbo stove, Progress in Thermochemical Biomass Conversion Conference, Tyrol, Austria.

[20] Sippula, O., Lamberg, H., Leskinen, J., Tissari, J. \& Jokiniemi, J. (2017) Emissions and ash behavior in a $500 \mathrm{~kW}$ pellet boiler operated with various blends of woody biomass and peat. Fuel, 202, 144-153.

[21] Suresh, R., Singh, V., Malik, J., Datta, A. \& Pal, R. (2016) Evaluation of the performance of improved biomass cooking stoves with different solid biomass fuel types. biomass and bioenergy, 95, 27-34.

[22] Varunkumar, S., Rajan, N. K. S. \& Mukunda, H. S. (2012) Experimental and computational studies on a gasifier based stove. Energy Conversion and Management, 53(1), 135-141.

[23] Zainal, Z., Rifau, A., Quadir, G. \& Seetharamu, K. (2002) Experimental investigation of a downdraft biomass gasifier. Biomass and Bioenergy, 23(4), 283-289. 